\title{
A Review of Blood and Blood Products Requisition and Utilization in Post- neonatal Ward of a Tertiary Hospital in South Western Nigeria
}

\author{
Akodu SO, Adekanmbi FA, Ogunlesi TA \\ Department of Paediatrics, Olabisi Onabanjo University Teaching Hospital, Sagamu, \\ Ogun State, Nigeria. \\ Correspondence to: \\ Samuel Olufemi Akodu \\ Department of Paediatrics, OOUTH Sagamu, Ogun State \\ Phone: +2348023187026 \\ Email:femiakodu@hotmail.com
}

\begin{abstract}
Background: Blood and its products ordering is a common practice in paediatrics. The ready availability of blood and blood components has resulted in liberal use. Inappropriate use of blood and blood products exposes patients to risk of transfusion transmissible diseases, and allergic and haemolytic reactions.
\end{abstract}

Objective: To assess blood and blood products requisition and utilization in a post-neonatal ward in a semi-urban tertiary hospital in Nigeria

Methods: Retrospective analysis of medical records of all transfused post-neonatal patients during the study period from $1^{\text {st }}$ July 2015 to $31^{\text {st }}$ December 2016 to calculate the cross match to transfusion ratio, transfusion probability and transfusion index.

Results: The units of blood cross matched were 98 and 90 blood units transfused. The cross-match to transfusion ratio was 1.09 indicative of significant blood usage. The transfusion probability was $100 \%$ indicative of significant blood usage. The transfusion index was 1.10 indicative of significant blood utilization.

Conclusion: Transfusion of blood and blood products in the postneonatal ward of our setting meet the standard criteria for quality indicators for blood utilization.

Keywords: Blood supply; Blood use; Cross-match to transfusion ratio; Transfusion probability; Transfusion index;

\section{Introduction}

Anaemia is a common clinical problem seen in everyday paediatric practice ${ }^{1}$ and blood transfusion is an integral part in its management. The number of patients requiring blood transfusions is increasing, while the donor pool is slightly decreasing or remains unchanged. ${ }^{2}$ Annually, about half a million units of blood are supplied by blood banks nationwide in Nigeria but this is insufficient to meet the annual blood needs of one and a half million. ${ }^{3}$ The appropriate transfusion of blood and blood products are not limited to the indication for the transfusion alone but also include the volume to be transfused. ${ }^{4}$ It has been 
documented that physicians usually order more units of blood than the patients will receive to provide safety margin in an event of unexpected haemorrhage

The disproportionateness of cross matched blood to requirements has been described as inefficient utilization of blood bank services. ${ }^{6}$ The unutilized blood and blood products ordered are not available for usage by other patients. A study conducted at the University of Benin Teaching Hospital Blood Bank revealed that the probability that cross-matched blood might not be used was high as $61 \%$ in the paediatric unit. ${ }^{7}$ The aim of this study was to assess blood and blood products requisition and utilization in a postneonatal ward in a semi-urban tertiary hospital in western Nigeria with a view to minimize waste and maximize the use of scarce donated blood..

\section{Methods}

The study was a cross sectional one using secondary data abstraction conducted in the post-neonatal Unit of the Olabisi Onabanjo University Teaching Hospital, Sagamu over an 18 month period from $1^{\text {st }}$ July 2015 to $31^{\text {st }}$ December 2016. The study subjects were all children admitted and transfused at the post-neonatal unit during the study period. The patients' medical records and transfusion request forms for all the transfused hospitalized children were extracted and entered into a predesigned questionnaire.

Olabisi Onabanjo University Teaching Hospital, Sagamu is the only state government-owned tertiary hospital in Ogun State. The hospital provides general paediatric and specialist services to all categories of children referred from within the hospital and those referred from other government-owned or privately-owned health facilities based in the State as well as neighboring states of the nation. The Paediatrics Department has three wards: children's emergency, neonatal and postneonatal wards. The post-neonatal ward has an average of 387 admissions annually. The independent variables were data obtained from patients' medical records and transfusion requests which were the patients' bio-data, packed cell volume (PCV), number of units cross matched, volume of blood crossmatched, number of units transfused, volume of blood transfused, underlying medical condition and the type of blood transfused. The primary outcome variables were the various quality indicators for blood utilization calculated as:

- Crossmatch to transfusion ratio $(\mathrm{CT}$ ratio $)=$ number of units cross matched divided by number of units transfused. ${ }^{9}$ A ratio of $<2.5$ is considered indicative of efficient blood usage. ${ }^{8}$ It is a novel method of measuring the efficiency of cross-matching procedure. ${ }^{9}$

- Transfusion Probability $(\%)=$ number of patients transfused divided by number of patients cross matched multiply by $100 .^{8} \mathrm{~A}$ value of $>30 \%$ was considered indicative of significant blood usage. ${ }^{8}$

- Transfusion index $=$ number of units transfused divided by number of patients transfused. ${ }^{8}$ A value of $>$ 0.5 was considered indicative of significant blood utilization. ${ }^{8}$

The secondary outcome variable was the trigger for use of blood and blood products determined using the haemoglobin concentration. Ha emoglobin concentration below $11 \mathrm{~g} / \mathrm{dL}$ was regarded as anaemia. ${ }^{10}$ The patients severity of anaemia was classified as mild, moderate and severe if the haemoglobin concentration are $10-10.9 \mathrm{~g} / \mathrm{dL}, 7.0-$ $9.9 \mathrm{~g} / \mathrm{dL}$ and $<7.0 \mathrm{~g} / \mathrm{dL}$ respectively. ${ }^{10}$

Statistical Package for the Social Sciences (SPSS) analytical software version 21 
(Chicago, Illinois, USA) was used to perform the statistical analysis. Frequencies were calculated for all variables and Pearson's Chi-square test was used to assess the statistical significance of difference in blood utilization. A $P$ value less than 0.05 was considered statistically significant.

Ethical clearance was obtained from Ethical and Research Committee of Olabisi Onabanjo University Teaching Hospital, Sagamu. Confidentiality of the information was assured by using code numbers rather than personal identification names and keeping questionnaires secured. There was no external funding for the study.

\section{Results \\ Triggers for use of blood and blood products}

During the study period there were 710 paediatric admissions into the postneonatal ward of the hospital with 82 patients transfused with blood and blood products. A total of 90 transfusions were given amongst these 82 patients. Eighty $(88.9 \%)$ of the ninety transfusion sessions were associated with varying degrees of anaemia. About three-quarter $(74.5 \%)$ of the transfusions were associated with severe anaemia and this observation was significant $(p=<0.001)$. The most prevalent haemoglobin trigger for blood transfusion was severe anaemia in all clinical conditions except for patients with G6PD deficiency and intususception ( $\mathrm{p}=$ 0.002). The haemoglobin trigger for transfusion of blood and blood products in our setting is shown in Table 1.

\section{Blood ordering and transfusion pattern}

As shown in Table 1, a total of 98 units of blood and blood products were crossmatched. However, only 90 units $(91.8 \%)$ were transfused. Packed red cells was the blood type with the highest number of blood and blood products unit crossmatched and transfused, while plasma and platelet concentrate were the lowest number of blood and blood products unit cross-matched and transfused. Malaria among clinical conditions indicated for blood transfusion had the highest number of units of cross-matched and transfused blood. This was followed by septicaemia with 20 units of blood cross matched, and only 17 units transfused.

A total of $48,560 \mathrm{ml}$ of blood and blood products were cross-matched, however, only $30,037 \mathrm{ml}(61.9 \%)$ were transfused. Packed red cells was the blood type with the highest volume of blood and blood products cross-matched and transfused, while plasma and platelet concentrate was the lowest volume of blood and blood products cross-matched and transfused. Malaria among clinical conditions indicated for blood transfusion had the highest volume of cross-matched and transfused blood. This was followed by septicaemia with $10,000 \mathrm{ml}$ of blood cross matched, and only $6,489 \mathrm{ml}$ transfused.

Age group $1-10$ years had the highest number of units of cross-matched and transfused blood. This was followed by infancy group with 21 units of blood cross matched, and only 20 units transfused. Age group $1-10$ years had the highest volume of blood and blood products crossmatched and transfused, while $>10$ years age category and infancy had the lowest volume of blood and blood products crossmatched and transfused respectively.

\section{Blood utilization pattern}

The calculated indicators for blood utilization are shown in Table 3. The overall cross-match-to-transfusion ratio (C:T ratio), transfusion probability, and transfusion index were $1.09,100.0 \%$, and 1.10 respectively. In relation to crossmatch-to-transfusion ratio ( $\mathrm{C}: \mathrm{T}$ ratio), 
plasma, children with AIDS, age group $>10 y e a r s$ and females had the highest ratio. The transfusion probability was $100 \%$ irrespective of blood type, clinical conditions, age group or gender. In relation to transfusion index, the ratio was highest for platelet concentrate, children with cancer, age category $>10$ years and females.

Distribution of blood ordered and utilized among subjects according to pre-transfusion hamoglobin concentration

The blood ordering and utilization pattern among eighty patients whose pretransfusion haemoglobin concentration was seen in their medical records was as shown in Table 4. For patients with documented anaemia, 87 blood units and $43,000 \mathrm{ml}$ of blood and blood products were cross-matched while only 80 units
$(92.0 \%)$ and $25,773 \mathrm{ml}(59.9 \%)$ were transfused to only 73 patients.

More units of blood was cross matched than the unit transfused among subjects with mild or severe anaemia while the mean units of blood cross matched was same as mean units transfused among subjects with moderate anaemia. The volume of blood cross matched was more than the volume transfused irrespective of the degree of anaemia among study subjects. The mean cross matched to transfusion ratio was below 2.5 indicative of efficient blood usage among subjects with severe anaemia compared with subjects having mild to moderate anaemia where it was 2.5 and above. The transfusion probabilities and transfusion index were fairly same irrespective of the type of anaemia.

Table 1: Triggers for use of blood and blood products in the ward

\begin{tabular}{|c|c|c|c|c|c|c|}
\hline & & $\begin{array}{l}\text { Mild } \\
\text { Anaemia }\end{array}$ & $\begin{array}{l}\text { Moderate } \\
\text { Anaemia }\end{array}$ & $\begin{array}{l}\text { Severe } \\
\text { Anaemia }\end{array}$ & $\begin{array}{l}\text { No Pre } \\
\text { transfusion } \\
\text { PCV } \\
\text { records }\end{array}$ & $\mathrm{p}$ value \\
\hline \multirow[t]{6}{*}{ Blood Products } & & & & & & $<0.001$ \\
\hline & Packed Red Cells & $0(0.0)$ & $7(12.1)$ & $44(75.9)$ & $7(12.0)$ & \\
\hline & Plasma & $1(33.3)$ & $1(33.3)$ & $0(0.0)$ & $1(33.3)$ & \\
\hline & Platelets Concentrate & $0(0.0)$ & $1(50.0)$ & $1(50.0)$ & $0(0.0)$ & \\
\hline & Whole Blood & $0(0.0)$ & $3(11.1)$ & $22(81.5)$ & $2(7.4)$ & \\
\hline & All & $1(1.1)$ & $12(13.3)$ & $67(74.5)$ & $10(11.1)$ & \\
\hline Clinical & & & & & & 0.002 \\
\hline \multirow[t]{11}{*}{ Condition } & AIDS & $0(0.0)$ & $0(0.0)$ & $1(50.0)$ & $1(50.0)$ & \\
\hline & Cancer & $0(0.0)$ & $0(0.0)$ & $5(100.0)$ & $0(0.0)$ & \\
\hline & G6PD Deficiency & $0(0.0)$ & $1(25.0)$ & $1(25.0)$ & $2(50.0)$ & \\
\hline & Intussusception & $0(0.0)$ & $1(100.0)$ & $0(0.0)$ & $0(0.0)$ & \\
\hline & Malaria & $0(0.0)$ & $2(8.3)$ & $20(83.4)$ & $2(8.3)$ & \\
\hline & Renal Disease & $1(9.1)$ & $2(18.2)$ & $6(54.5)$ & $2(18.2)$ & \\
\hline & Septicaemia & $0(0.0)$ & $5(27.8)$ & $12(66.7)$ & $1(5.5)$ & \\
\hline & Severe malnutrition & $0(0.0)$ & $1(12.5)$ & $7(87.5)$ & $0(0.0)$ & \\
\hline & Sickle Cell Disorder & $0(0.0)$ & $0(0.0)$ & $14(87.5)$ & $2(12.5)$ & \\
\hline & Tuberculosis & $0(0.0)$ & $0(0.0)$ & $1(100.0)$ & $0(0.0)$ & \\
\hline & All & $1(1.1)$ & $12(13.3)$ & $67(74.5)$ & $10(11.1)$ & \\
\hline
\end{tabular}

NB: Values in parenthesis are $\%$ of number in roll 
Journal of Epidemiological Society of Nigeria Vol. 4 No.1 June. 2021 97-107

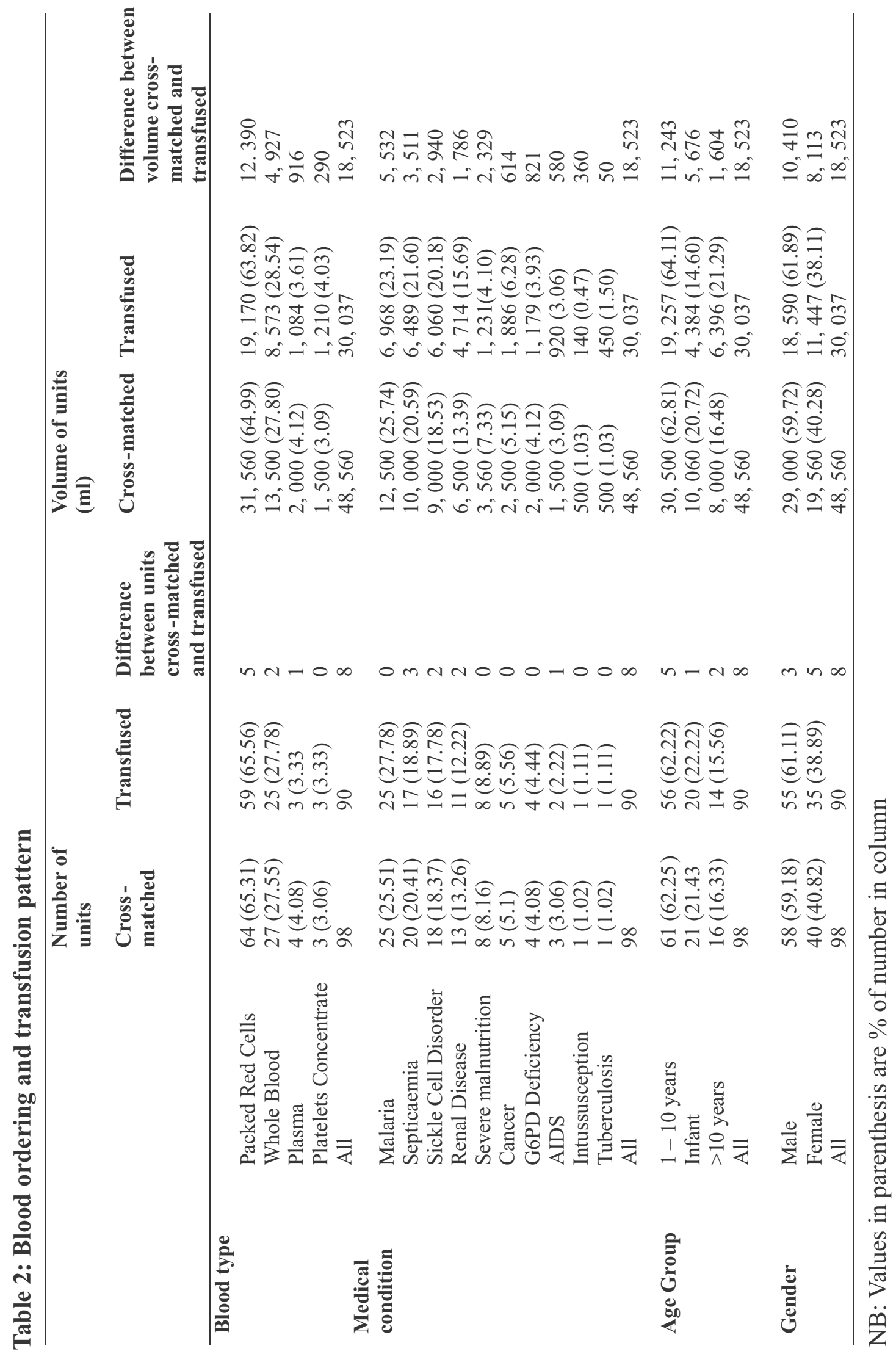


Table 3: Blood utilization pattern

\begin{tabular}{|c|c|c|c|c|}
\hline & & $\begin{array}{l}\text { Cross-match } \\
\text { to transfusion } \\
\text { ration }\end{array}$ & $\begin{array}{l}\text { Transfusion } \\
\text { Probability } \\
(\%)\end{array}$ & $\begin{array}{l}\text { Transfusion } \\
\text { Index }\end{array}$ \\
\hline \multicolumn{5}{|l|}{ Blood type } \\
\hline & Packed Red Cells & 1.08 & 100.00 & 1.05 \\
\hline & Plasma & 1.33 & 100.00 & 1.00 \\
\hline & Platelets Concentrate & 1.00 & 100.00 & 1.50 \\
\hline & Whole Blood & 1.08 & 100.00 & 1.19 \\
\hline & All & 1.09 & 100.00 & 1.10 \\
\hline \multicolumn{5}{|l|}{ Medical condition } \\
\hline & AIDS & 1.50 & 100.00 & 1.50 \\
\hline & Cancer & 1.00 & 100.00 & 1.67 \\
\hline & G6PD Deficiency & 1.00 & 100.00 & 1.33 \\
\hline & Intussusception & 1.00 & 100.00 & 1.00 \\
\hline & Malaria & 1.00 & 100.00 & 1.09 \\
\hline & Renal Disease & 1.18 & 100.00 & 1.30 \\
\hline & Septicaemia & 1.18 & 100.00 & 1.33 \\
\hline & Severe malnutrition & 1.00 & 100.00 & 1.00 \\
\hline & Sickle Cell Disorder & 1.13 & 100.00 & 1.13 \\
\hline & Tuberculosis & 1.00 & 100.00 & 1.00 \\
\hline & All & 1.09 & 100.00 & 1.10 \\
\hline \multicolumn{5}{|l|}{ Age Group } \\
\hline & Infant & 1.05 & 100.00 & 1.05 \\
\hline & $1-10$ years & 1.09 & 100.00 & 1.12 \\
\hline & $>10$ years & 1.14 & 100.00 & 1.33 \\
\hline & All & 1.09 & 100.00 & 1.10 \\
\hline \multicolumn{5}{|l|}{ Gender } \\
\hline & Male & 1.05 & 100.00 & 1.14 \\
\hline & Female & 1.14 & 100.00 & 1.29 \\
\hline & All & 1.09 & 100.00 & 1.10 \\
\hline
\end{tabular}


Table 4: Distribution of blood ordered and utilized among subjects according to pre-transfusion haemoglobin concentration

\begin{tabular}{llll}
\hline & \multicolumn{1}{c}{ Mild anaemia } & $\begin{array}{l}\text { Moderate } \\
\text { anaemia }\end{array}$ & Severe anaemia \\
\hline $\begin{array}{c}\text { Number of unit } \\
\text { Cross-matched }\end{array}$ & $2(2.30)$ & $11(12.64)$ & $74(85.06)$ \\
$\begin{array}{l}\text { Transfused } \\
\text { Volume of unit (m) }\end{array}$ & $1(1.25)$ & $11(13.75)$ & $68(85.00)$ \\
$\quad$ Cross-matched & $1,000(2.32)$ & $5,500(12.79)$ & $36,500(84.89)$ \\
$\quad \begin{array}{l}\text { Transfused median } \\
\text { Cross-match to transfusion ratio }\end{array}$ & 2.00 & $2,735(10.61)$ & $22,638(87.84)$ \\
Transfusion Probability (\%) & 100.00 & 100.00 & 1.09 \\
Transfusion Index & 1.00 & 1.00 & 1.10 \\
\hline
\end{tabular}

NB:Values in parenthesis are $\%$ of number of total units/volume

\section{Discussion}

The number of patients requiring transfusion with blood and blood products is increasing and this demand exceeds the available donated blood and blood products available in the blood bank. ${ }^{11}$ Medical doctors while preparing for the transfusion session tend to overestimate the anticipated blood requirements. It is essential that the usage of blood and blood products should be rationalised and saved for critical situations. Blood is a precious gift that is not meant to be wasted. Blood ordering and transfusion audit is an important measure that needs to be carried out regularly in all clinical units that offer transfusion services including postneonatal wards. These audits serve as a surveillance tool which can help in formulating guidelines for blood ordering and transfusions.

The study showed a blood and blood products transfusion request of ninety which was lower than the 372 earlier reported among children population in Federal Medical Centre, Birnin Kudu. ${ }^{12}$ This difference may be related to the study duration and the age range of the recruited study subjects. The Birnin Kudu study recruited participants including the neonates over a one year period culminating in the higher yield of request for blood and blood products. The present study revealed that severe anaemia was the most important haemoglobin trigger for the transfusion of packed red cells and whole blood. This did not differ according to the underlying clinical condition group. The recommended cut-off for red cell transfusion is at a level below $7 \mathrm{~g} / \mathrm{dL}$ which is classified as severe anaemia. ${ }^{13}$ Children seem to be capable in their ability to compensate for lower haemoglobin concentration by increased oxygen extraction and cardiac output..$^{14}$ A previous study had reported anaemia as the most common indication for blood transfusion within the sub-saharan region. ${ }^{12}$ 
Other blood products such as fresh frozen plasma and platelet concentrate are occasionally used in our post-neonatal paediatric ward. This may be attributed to the absence of centrifuge machine to separate the blood components from the whole blood in the study centre with such prescriptions being changed to whole blood most often. The platelet concentrate is usually required in a bleeding patient below a platelet count of $50 \times 10^{9} / \mathrm{L}$ but rarely above $100 \times 10^{9} / \mathrm{L}^{15}$

A comment on the use of blood and blood products according to clinical conditions is desirable as it was observed that malaria accounted for about one-quarter of the subjects who received blood transfusions. This finding showed that malaria is the most common clinical condition in our setting responsible for anaemia which necessitated the use of blood transfusions. This finding is consistent with the finding in Yaoundé, Cameroun. ${ }^{16}$

The present study revealed that the most cross matched and transfused blood products were packed cell volume. This is similar to report by previous authors ${ }^{12}$ in resource poor settings where severe anaemia from haemolysis by infection and infestation still remains an important trigger for transfusions of blood and blood products.

The cross match to transfusion (CT) ratio, the transfusion probability $(\% \mathrm{~T})$ and the transfusion index (TI) are indices employed to evaluate utilization of blood. . Ablood cross match is justified in a clinical condition that carry a cross match to transfusion (CT) ratio $<3$, transfusion probability $(\% \mathrm{~T})>30 \%$ or a transfusion index (TI) $>0.5 .{ }^{5,8,9,}$ The cross match to transfusion (CT) ratio could be a useful transfusion service quality indicator, since it reflects how often a cross match is performed compared with how many blood and blood products are actually issued and transfused. ${ }^{17}$
This study demonstrates that cross matching blood for use in our postneonatal ward exceeds requirement considerably - a practice we suspect is widespread within our healthcare system. Children who need blood and blood products transfusion receive a calculated volume of blood and blood products depending on their weight to achieve a target haemoglobin concentration. Any miscalculation of this volume is capable of leading to either inadequate or excessive transfusions which makes the volume calculation formula crucial. These findings though not comprehensive, strengthen the case for the establishment of institutional maximum blood ordering schedule by hospital transfusion committees. The schedule should be regularly monitored and evaluated to verify compliance and updated as at when necessary. The potential benefits include improved availability of a vital resource and financial savings through prevention of donated blood wastage. The excess requested and issued of blood and blood products was more pronounced with packed red cells and within the age group $1-10$ years.

The average cross match to transfusion ratio of 1.09 observed in this study is an indication of efficient and effective utilization of blood and blood products which is a commendable standard when compared to other centres within and outside Nigeria with cross match to transfusion ratio of greater than 2.0. ${ }^{18,} 19$ The reason for the lower ratio in the current study may be attributed to the exclusion of the neonatal age group in the study subjects unlike the north-western and south-south studies. The closer the crossmatch to transfusion ratio is to $1: 1$, the more accurately the physicians predict patient's blood needs and this signifies efficient hospital transfusion policy and practice. The observed difference in cross match to transfusion ratios across studies 
may be due to different transfusion policies at different hospitals and physicians transfusion practice which are not comparable.

This study revealed that for the given period in this post-neonatal ward the average transfusion probability was $100 \%$. Accordingly, a value of $30 \%$ and above has been suggested to be appropriate and signifies the appropriateness of number of units' cross matched. ${ }^{5,8,20}$. Based on this criterion, the results of the present study of an overall transfusion probability of $100 \%$ was indicative of appropriate utilization of units of blood cross matched. This finding was higher than $62 \%$ and $69 \%$ reported in 2013 and 2017 respectively in an audited analysis of forms of blood and blood products of Mofd Children's Hospital. ${ }^{21}$ The observed difference in rate may be due to the relatively small number of transfusion sessions used to calculate the blood indices in the current study since small sample size will result in an exaggerated rate.

Regarding transfusion index, a value of 0.5 or more is indicative of efficient blood usage and signifies the appropriateness of number of units' transfused. ${ }^{8,22}$ The overall transfusion index reported in the current study was 1.10. Transfusion index of patients admitted into the post-neonatal ward under the current study was considered appropriate. The reported transfusion index of 0.83 and 0.97 in 2013 and 2017 respectively in an audited analysis of forms of blood and blood products of Mofd Children's Hospital was lower than that found in the present study. ${ }^{21}$ The observed difference in ratio is an effect of the strength of the denominator which is the number of patients transfused with the cross matched blood. The number of patients transfused in the study in 2013 and 2017 are 10,472 and 14,775 respectively. ${ }^{21}$
In conclusion, the blood ordering pattern in our setting needs to be revised in order to minimize over ordering of blood. Our results show that $100 \%$ of cross matched blood is utilized; this is a reflection of efficient blood usage practice. The computed blood indices $(\mathrm{C} / \mathrm{T}$ ratio, $\% \mathrm{~T}$, and TI) are optimal. Commonly demanded and issued components were packed red cells and whole blood. The current study demonstrated that over ordering of blood and blood practice was a prominent practice. The protocol for ordering of blood and blood products in patients in terms of volume to be transfused needs to be revised to minimize blood wastage.

This study has some limitations. The main limitation is the relatively small number of transfusion sessions used to calculate the blood indices. A larger transfusion session would have permitted a more accurate assessment of any statistical difference in the blood indices. Thus, the statistical analysis presented in this article must be interpreted with caution; it is provided to give the reader a sense of the blood and blood products requisition and utilization practice in post-neonatal ward in a semiurban tertiary hospital in Nigeria. With a larger sample size, different trends might become apparent. Since we have not scientifically estimated the minimum sample size for this study, it is imperative to mention that this may also limit the generalization of the findings of this study.

\section{Source of funding:}

None

\section{References}

1. Ekwochi U, Osuorah DIC, Odetunde OI, Egbonu I, Ezechukwu CC. Prevalence of iron deficiency anaemia in anaemic under-5 children in Enugu South East Nigeria. Niger J Paed 2014; 41 (2): 129-132

2. Durandy Y. Use of Blood Products in Pediatric Cardiac Surgery. Artificial 
Organs. 2015;39(1):21-7

3. Okpe ES, Abok' I.' Dia!a UM, Okolo SN,' Joseph DE. Indications for Blood Transfusion among Children in a Tertiary Hospital in North-Central Nigeria. Journal of Medicine in the Tropics 2011; 13:2: 95 - 7

4. World Health Organization. Blood Safety and availability Fact sheet: Department of blood transfusion safety and clinical technology. WHO Geneva 2011

5. Zewdie K, Genetu A, Mekonnen Y, Worku T, Sahlu Abat, Gulilalt D. Efficiency of blood utilization in elective surgical patients. BMC Health Serv Res 2019; 19: 1 -7

6. Murugesan M, Subbiah SP. Blood Requisition and Utilization Practice in Obstetric Patients at Tertiary Care Center from South India: A Descriptive Study. Journal of Applied Hematology 2018; 9 (4): 131 - 5

7. Enosolease $\mathrm{ME}$, Imarengiaye $\mathrm{CO}$. Blood shortage situation: An audit of red blood cells order and pattern of utilization. African Journal of Biotechnology 2009; 8 (21): 5922 - 5 .

8. . Guzman JPS, Resurreccion LL, Epte MBP. Use of Maximum Surgical $\mathrm{O} \mathrm{r} \mathrm{d} \mathrm{e} \mathrm{r} \quad \mathrm{S} \mathrm{ch} \mathrm{e} \mathrm{d} \mathrm{u} \mathrm{le}$ (MSBOS) among pediatric patients to optimize blood utilization. Annals of Pediatric Surgery 2019; 15 (4): 1 -5

9. Yazer MH, Alcantara R, Beizai P, et al. Use of a Novel Quality Indicator and Results of an International Survey on $\mathrm{RBC}$ Crossmatching and Issuing Practices. Am J Clin Pathol 2016; 146: 238 - 43

10. Behera S, Bulliyya G. Magnitude of Anemia and Hematological Predictors among Children under 12 Years in Odisha, India. Anemia 2016; 2016: $1-10$

11. Basnet RB, Lamichhane D, Sharma VK. A Study of blood Requisiton and transfusion Practce in Surgery at bir Hospital. PMJN 2009; 9 (2): 14-19

12. Aliyu I, Michael G, Ibrahim H, Ibrahim ZF, Aliyu G, Isaiah AT. Blood transfusion request pattern in a medical center in Northwestern Nigeria. Glob J Transfus Med AATM 2017; 2: $52-5$.

13. Dellinger RP, Levy MM, Carlet JM, et al. Surviving Sepsis Campaign: international guidelines for management of severe sepsis and septic shock: 2008. Crit Care Med 2008; 36:296e 327.

14. Ali N. Red blood cell transfusion in infants and children - Current perspectives. Pediatrics and Neonatology 2018; 59 (3): 227 - 230

15. Yaddanapudi S, Yaddanapudi LN. Indications for blood and blood product transfusion. Indian J Anaesth 2014; 58: 538- 42

16. Ayuketah PO, Tagny CT, Koki NP. Assessment of Clinical Blood Transfusion Practice in a Pediatric Tertiary Hospital in Cameroon. Journal of Blood Disorders and Therapeutics 1 (1): $1-5$

17. Yazer M H, Alcantara R, Beizai $P$, et al. Use of a Novel Quality Indicator and Results of an International Survey on RBC Crossmatching and Issuing Practices. Am J Clin Pathol 2016;146:238-243

18. Musa AU, Ndakotsu MA, Hassan A, Kilishi A, Kwaifa IK. Pattern of blood transfusion request and utilization at a Nigerian University Teaching Hospital. Sahel Med J 2014; 17: 19 22

19. Ebose E M, Osalumese I C. Blood shortage situation: An audit of red blood cells order and pattern of utilization. African Journal of Biotechnology 2009; 8 (21): 5922 5925

20. Trisal M, Rana S, Khertrapal S, Jetley 
S, Mohroo RN, Jairajpuri Z. Blood utilization practices and quality indicators at a tertiary care hospital in South Delhi - A retrospective study. National Journal of Laboratory Medicine 2020; 9(2): 1 -3

21. Karbasian F, Zafari A, Goudarzipour K, Mesdaghi M, Shariatadeh S, Eshghi P. Evaluation of Changes in Blood Products Transfusion Indices
Following Three Years of Implementation of Iranian Blood Transfusion Organization Standards. IJBC 2019; 11 (4): 133 - 138

22. Belayneh T, Messele G, Abdissa Z, Tegene B. Blood requisition and utilization practice in surgical patients at University of Gondar Hospital, Northwest Ethiopia. Journal of Blood Transfusion 2013; 2013: 1 - 5 